\title{
Exclusive breastfeeding practice and its associated factors among mothers with infants aged less than six months in Nono, Western Ethiopia: A cross- sectional study
}

\section{Gerba Fufa}

West Shewa Zonal Health Department, Ambo, Ethiopia

Tesfaye Solomon ( $\square$ abdiikoo50@gmail.com )

Ethiopian Public Health Institute, Addis Ababa, Ethiopia https://orcid.org/0000-0003-0994-393X

Teka Girma

Public Health Department, Ambo University, Ambo, Ethiopia

\section{Research Article}

Keywords: Exclusive breastfeeding, factors, practice, Ethiopia

Posted Date: June 4th, 2021

DOl: https://doi.org/10.21203/rs.3.rs-590282/v1

License: (c) (1) This work is licensed under a Creative Commons Attribution 4.0 International License.

Read Full License 


\section{Abstract \\ Background}

Exclusive breastfeeding is the best and cost effective intervention to prevent childhood morbidities and mortalities in developing countries. But there was no evidence in the study area regarding the practice of exclusive breastfeeding and its associated factors. Therefore, this study was aimed to assess exclusive breastfeeding practice and its associated factors in a rural district, Western part of Ethiopia.

\section{Methods}

A community-based cross-sectional study was conducted from August 15-30, 2020 among 565 mothers who have an infant less than six months in Nono District. Study participants were selected using random sampling. Data on infant breastfeeding practice were collected by trained interviewers by using a structured questionnaire. Multivariable logistic regression analysis was used to determine factors associated with exclusive breastfeeding. Statistical significance was declared at $P<0.05$ at $95 \%$ confidence interval.

\section{Results}

A total of 565 participants were participated in this study, giving a $95.9 \%$ response rate. The prevalence of exclusive breastfeeding practice was $70.8 \%$. Age of Mothers $(\mathrm{AOR}=2.67,95 \% \mathrm{Cl}=1.79,4.60)$, attended antenatal care during the recent pregnancy $(A O R=2.31,95 \% \mathrm{Cl}=1.31,4.71)$, attended delivery in health facilities $(A O R=1.34,95 \% \mathrm{Cl}=1.21,2.11)$, having information about exclusive breastfeeding $(\mathrm{AOR}=2.34$, $95 \% \mathrm{Cl}=1.13,4.76)$ and knowing the importance of exclusive breastfeeding $(\mathrm{AOR}=1.46,95 \% \mathrm{Cl}=1.12$, 3.73) were associated factors with exclusively breastfeeding.

\section{Conclusions}

The prevalence of exclusive breastfeeding among infants less than six months in the Nono district was $70.8 \%$. Factors associated with exclusive breastfeeding were the age of mothers, antenatal care service utilization, place of birth, mothers' information about breastfeeding, and knowledge of mothers about the importance of exclusive breastfeeding. Therefore, it is recommended that awareness should be continuously raised and pregnant women should be encouraged to attend health facilities for antenatal care and delivery by health service providers hence improving exclusive breastfeeding.

\section{Background}

Exclusive breastfeeding (EBF) has been defined by the World Health Organization (WHO) as the infant has received only breast milk from his/her mother or a wet nurse, or expressed breast milk, and no other 
liquids or solids, except for drops or syrups consisting of vitamins, mineral supplements or medicines (1).

Studies have demonstrated that it reduces deaths in infants and young children (2), especially it prevents death in low and middle-income countries due to preventable causes $(3,4)$. EBF has important benefits for both the mother and child (5). Babies who are breastfed exclusively for six months experience fewer illnesses because breast milk contains nutrients and substances that protect the baby from several infections and major childhood conditions, and it leads to improved cognitive development (6).

Breastfeeding is a well-established and recommended intervention for the improvement of child nutrition. EBF for the first six months of infants' life is a cost-effective intervention in saving children's lives and it is recommended by the WHO and United Nations International Children's Fund (UNICEF) that mothers initiate breastfeeding within the first hour after birth(7).

With exclusive breastfeeding universal coverage of $90 \%$, approximately $13-14 \%$ of the deaths of infants and young children less than five years of age can be prevented in low and middle-income countries (3). WHO has set a target to increase the EBF rate to $50 \%$ by 2025 to improve maternal and infant nutrition(8).

Initiation of breastfeeding immediately after birth can reduce the risk of neonatal mortality in the first week of life by $22 \%$ globally. Initiating breastfeeding in the first one hour after birth can decrease the risk of newborn infant mortality by about $45 \%$ and exclusively breastfed children were 14 times more likely to survive the first 6 months of life than non-breastfed children (9).

Despite the established benefits of optimal breastfeeding, about $60 \%$ of infants in developing countries are not exclusively breastfed for six months and suboptimal breastfeeding is the major cause of over $30 \%$ of child deaths, especially in low-income settings (10). Previous studies carried out showed that $39 \%$, $35 \%$, and $52 \%$ of infants less than six months received exclusive breastfeeding in developing countries, Africa and Ethiopia respectively (11).

Despite the prevalence of breastfeeding is common in Ethiopia; the practice of exclusive breastfeeding among 0-6months age children differs by region. According to Ethiopian Demographic and Health Survey 2016 nearly all children, i.e., $97 \%$ are breastfed at some points while only $58 \%$ of infants below the age of six months are exclusively breastfed (9). These demonstrate that most women do not practice EBF for six months despite breastfeeding practice is a vital component of primary health care. Hence, this study comes up with the magnitude and determinants of exclusive breastfeeding practice in the study area, which helps to promote exclusive breastfeeding practices for the first six months of infant life.

\section{Methods}

\section{Study area}

The study was conducted in the Nono District of West Shewa Zone, Oromia Regional State, Western part of Ethiopia. Nono district is located $214 \mathrm{~km}$ away from Addis Ababa, the capital city, and $100 \mathrm{~km}$ away 
from Ambo, a zonal town. The district has four health centers and 33 health posts that provide primary health services to the community. Based on the 2007 national census conducted by the Central Statistical Agency of Ethiopia, the district has a total population of 117,395 of which $50 \%$ are female, and 1303 are children less than six months of age(12). Even though breastfeeding is a common experience, there was no evidence on exclusive breastfeeding in the district. Hence, the study area was designed to fill this gap.

\section{Study design and period}

A community-based cross-sectional mixed with the qualitative study was conducted. Randomly selected mothers who had an infant less than six months old available at the time of data collection and who lived in the study area were included in this study. Mothers who were severely ill, unable to give the required information, or not presented at home with two visits were excluded. Data were collected from August 15-30th, 2020.

\section{Study Variables}

Dependent variable: Exclusive breastfeeding practice

The independent variables were as follows:

\section{Maternal related factors}

Include age of mothers, marital status, educational status of mothers, occupation of mothers, mother's knowledge on breastfeeding, and maternal illness.

\section{Obstetric \& health service-related factors}

Include parity, antenatal care, breastfeeding counseling during pregnancy, place of delivery, mode of delivery, and postnatal care.

\section{Infant-related factors}

Include age of the infant, sex of infant, birth order, birth interval, colostrum feeding status, and infant illness.

\section{Sample size determination}

The sample size was calculated by Epi-info version 7 for the prevalence of EBF practice using the single population proportion formula by considering the following assumptions: $95 \%$ level of confidence, $5 \%$ margin of error, and $58 \%$ prevalence of exclusive breastfeeding (9). After considering a $5 \%$ non-response rate and design effect of 1.5, the final sample size was 589 .

\section{Sampling techniques}

Ten kebeles (28.5\%) out of 35 kebeles in the district were selected randomly, supposing they were representative enough. The total sample size was allocated proportionally to the total number of mothers 
who had had a child less than 6 months in each selected kebele. A list of mothers who had children less than six months were collected from Community Health Information System available at the nearby health post and was used as a sampling frame. Finally, study subjects were selected using a simple random sampling method i.e. a lottery method was used. If more than one mother had an infant less than six months old found in the same house, then the mother with the youngest child was selected. The lottery method was used if mothers had a child of the same age.

The purposive sampling technique was used to select study subjects for qualitative study. Four (two women and two men) focus group discussions (FGD) in which 8-12 participants of women currently breastfeeding infants were selected to participate from kebeles in which quantitative data was not collected. Individuals of similar backgrounds and residents of the study area for more than six months were included in the same group. For key informants (KI) interview experienced and well-informed health care workers were randomly selected from different health facilities.

\section{Data collection tool and techniques}

A structured questionnaire adapted from different works of literature was used to data about sociodemographic characteristics, maternal/infant health service utilization, breastfeeding practices and related factors, and barriers to exclusive breastfeeding.

For qualitative study data, the collection instrument was an interview guide for FGD and a semi-structured open-ended interview guide for a key informant. The questionnaire was originally prepared in English and translated into Afan Oromo by a language expert and back into English by another expert to ensure its consistency. The questionnaires were administered to mothers currently breastfeeding from the selected source population by trained data collectors through a face-to-face interview. Supervision was conducted on the process of the data collection. Ten trained health extension workers were recruited for data collection from nearby kebeles and supervised by three Public Health Officers and two BSc Nurse (1 supervisor per 2 data collectors) from the catchment health center.

For the qualitative part, the discussion guide was prepared in English and translated into Afan Oromo by a language expert. Then Afan Oromo was retranslated to English to ensure consistency. FGD was held in Afan Oromo and translated to English. The next completed transcription was compared with handwritten notes to fill inaudible phases or gaps in tapes. All FGDs and Kls were tape-recorded, after seeking oral consent from the participants.

\section{Data quality control and management}

Data collectors were trained for one day by the principal investigator $(\mathrm{PI})$ about the purpose of the study, how to approach the respondents and how to conduct the interview. Closer supervision was conducted during data collection. Each questionnaire was checked daily by the supervisors and randomly by the PI. The questionnaire was pre-tested on $5 \%$ of the total sample in a kebele out of those randomly selected for the study and accordingly, some amendments on jargon questions were made to regulate and ensure its validity. 


\section{Data analysis}

Each filled questionnaire was coded and checked manually for completeness and consistency. Then, the data entered into Epidata version 3.1 and exported to SPSS version 22 for further statistical analysis. Frequency distribution was done for categorical data. Measures of central tendency and measures of dispersion were computed for continuous variables. Bivariate analysis was done to select candidate variables with $\mathrm{P}<0.25$ and then entered into a multivariable logistic regression to control for confounding effects. In multivariable logistic regression, Adjusted Odds Ratio (AOR) with 95\% Confidence Interval (Cl) and $\mathrm{P}<0.05$ was set as a cut-off point to declare for the significance of the association between dependent and independent variables.

For qualitative data, the tape-recorded and note obtained from FGD's and KI's was transcribed by the principal investigator into Afan Oromo and arranged with the written notes taken at the time of discussion and interviewed. Then the obtained information was translated into English. The data were grouped based on thematic frameworks (thematic areas). Concepts were extracted from themes and presented in narratives, and data were categorized and analyzed thematically. A verbatim quotation was used to illustrate responses on relevant issues and themes. The results were presented in narratives and triangulated with the quantitative information to answer the research question.

\section{Operational Definitions}

\section{Exclusive breastfeeding}

If the infant fed only breast milk (except for ordered medicines and vitamins by health professionals) one day (24hrs) before the survey was conducted.

\section{Infant}

A person from birth to 12 months of age; and in this study children aged 0-6 months were considered as infants.

\section{Kebele}

The lowest government administrative hierarchy.

\section{Pre-lacteal feeding}

If an infant within the first three days of life feeds something other than breast milk.

\section{Timely initiation of breastfeeding}

If an infant within one hour (including one hour) of birth is put on the mother's breast to feed.

\section{Results}




\section{Socio-demographic characteristics}

In the study, 565 participants participated which made a response rate of $95.9 \%$. Concerning ethnicity, $463(81.9 \%)$ study participants were Oromo and 19 (16.1\%) were Amhara. The majority (58.4\%) were Orthodox in religion. Concerning the educational status of mothers, the majority (60.5\%) could not read and write. The mean age of the mothers was 28 years (standard deviation, SD \pm 5.0 ) (Table 1).

\section{Infant and maternal health service utilization characteristics}

The majority $(91.7 \%)$ of the mothers had an antenatal care visit during their recent pregnancy and were counseled about breastfeeding. More than half $(55.4 \%)$ of the mothers gave birth to their last child in health facilities (Table 2).

The qualitative finding proved that majority of the discussants mentioned the ideal desire of their exclusive breastfeeding and most of the women FGD discussants mentioned, "Breastfeeding is our culture". However, they perceived mixed feeding than exclusive breastfeeding. A 31 years old breastfeeding mother said, "We have been informed by health professionals that giving cow's milk and other foods even water to infants less than six months old is unnecessary". Women FGD discussants agreed, "Even if, majority of mothers attend antenatal care and get breastfeeding counseling, they did not apply exclusive breastfeeding practice properly".

The Men FGD discussants described exclusively breastfed babies as having higher intelligence, physically stronger, and protected from illness. Exclusively breastfed babies are described as much healthier than babies who started additional foods or liquids before six months of age.

\section{Knowledge about breastfeeding}

The majority, 564(99.8\%), of mothers had known the importance of breastfeeding. but $70(12.4 \%)$ of mothers had known the importance of breastfeeding which is very low. The majority $562(99.5 \%)$ of mothers knew to initiate breastfeeding immediately after birth.

A 27 years old mother explained her knowledge about the importance of breastfeeding for infant health as shown in the following extract. "Feeding a baby only breast milk for the first 6 months is becoming our culture due to the information we got from the health facility and the house-to-house visits of the health extension workers. Our current practice is only breast milk, no other additional foods for the first 6 months." Some women of FGD discussants mentioned that they do not know the importance of breastfeeding for maternal health.

\section{Exclusive breastfeeding practices}

The prevalence of exclusive breastfeeding practice was 400(70.8\%). Among mothers who did not exclusively breastfeed their infant, perception of breast milk only being not sufficient for the infant $113(68.5 \%)$ was the main reason mentioned. More than half, 328(58.1\%), of mothers have been advised about exclusive breastfeeding by their husbands (Table 3 ). 
In-depth interviews identified that poor knowledge was the main barrier to exclusive breastfeeding. For instance, a 29 years old rural health extension worker expressed that "Mothers do not consider breast milk as adequate and important."

Among qualitative findings, both men and women FGD discussants raised that the reasons for not exclusively breastfeeding were due to different perceptions of the community such as breast milk only not sufficient, babies thirsty unless they drink water, breast milk alone enough for only the first two months, and workload of mothers. The role of the father was as a supporter, the expectation being that they were responsible for financially supporting the family and enabling the purchase of food that would contribute to the health of the mother and their children. The men FGD discussants perceived that exclusive breastfeeding is important for babies but not for mothers. For example, a 24 years old breastfed mother explained, "The baby fed with breast milk for 6 months will have better health. If I breastfeed for six months, it will be good for the health of the baby but not for the mother."

Regarding the importance of breastfeeding for the mothers, the majority of men discussants perceived that mothers frequently breastfeeding their infants and breastfeeding for a long period were physically weak and ill.

EBF is a culturally acceptable practice among all of the participants. The majority 328 (58.1\%) of mothers were supported by their husbands to feed their infant exclusively on breast milk. Most 192 (34\%) of mothers had heard information about exclusive breastfeeding was from health providers.

A qualitative study showed that only a few fathers participate in caring for children in addition to financial supporting of the family. As FGD discussants mentioned that, they know different sources of information on the importance of breastfeeding such as health professionals, different Media such as television, radios, and their neighbors. However, most of them have not been following attentively this source of information regarding the importance of breastfeeding. For instance, a 37 years old man from the men FGD group said that "I have Television in my house, health extension workers also counseling our community on the importance of exclusive breastfeeding by going house to house but I didn't follow it due to workload as well as because of negligence by perceiving as it is important only for women."

A 35 years man FGD discussant mentioned on "Health posts didn't provide their duties regularly, it was closed on most of the working days, because of this my wife has interrupted her ANC follow up and gave birth at home". Majority of men FGD discussants mentioned that there was no health education given at the community level during different meetings, rather than during home visits. KI interview added, "Breastfeeding mothers experience several challenges in their quest to practice exclusive breastfeeding". These challenges include knowledge gaps especially for mothers who do not attend ANC follow-up.

\section{Barriers of exclusive breast-feeding}

Among the barriers mentioned by the participants, 22 (3.7\%) of mothers had experienced breastfeeding problems (like mastitis and soreness) and lack of organizational/social support for breastfeeding, 545 (96.5\%). The women FGD discussants said, "No adequate information about exclusive breastfeeding was 
provided to mothers from health care providers." Thus, mothers who were not breastfeeding infants were implemented properly. Most men FGD discussants said, "Health facilities only invite pregnant mothers during ANC follow up."

\section{Independent predictors of EBF}

Bivariate analysis was conducted to select candidate variables with P-value $<0.25$. Independent predictors of exclusive breastfeeding practice were determined using multivariable logistic regression. In the final model, variables with P-value $<0.05$ were considered significant.

In this study, the mother's age was found to be an independent predictor of EBF practice. Mothers in the age of 20-24 years interval were found more than two times more likely and exclusively breastfed their infant as compared to those breastfeeding mothers aged 35 and above years [AOR $=2.67(1.79,4.60)]$.

Mothers who had attended antenatal care services during their pregnancy exclusively breastfeed their infants two times more likely than mothers who were not attended antenatal care services during their pregnancy [AOR: $2.31(1.31,4.71)]$. Mothers who attended delivery in health facilities exclusively breastfeed their infant 1.34 times more likely as compared to mothers delivered at home [AOR: 1.34 (1.21, 2.11)].

Mothers who had information about exclusive breastfeeding were two times more likely to exclusively breastfeed than those mothers who had no information [AOR: $2.34(1.13,4.76)]$. Mothers who knew the importance of exclusive breastfeeding for maternal health were more than one times more likely to exclusively breastfed their infants up to six months of age when compared with breastfeeding mothers who hadn't the knowledge on the importance of exclusive breastfeeding of infants less than six months for maternal health [AOR: 1.46 (1.12-3.73)] (Table 4).

\section{Discussion}

The purpose of this study was to assess exclusive breastfeeding practice and associated factors during the first six months of age among breastfeeding mothers. This study revealed that the prevalence of EBF in the Nono district was $70.8 \% \%$. This finding is similar to a study conducted in Goba district, Ethiopia $(71.3 \%)(13)$, on the other hand, greater than studies in other parts of the country such as Bahirdar $(49.1 \%)(6)$, and Galkayo, Somali region (5.2\%) (3). However, the result of this study is lower than the study conducted in Ambo district (82.2\%) (14), Afar (81.1\%) (15), and Gozamin district (74.1\%) (16). Even though breastfeeding is common in the study area, the differences that enable or abandon mothers to EBF their infant during the first six months of age might due to socio-economic and demographic factors.

This study revealed that breastfeeding mothers aged 20-24 years had a 2.67 times chance of exclusively breastfeeding their infants who are less than six months years old as compared with breastfeeding mothers of 35 years old and above. This implies that exclusive breastfeeding has a negative association with maternal age. However, this study contradicts the study conducted in Brazil which shows adolescent 
mothers had a 1.5 times greater risk of abandoning EBF before their babies were six months of age when compared with adult women (17). The differences might be due to the difference in the study settings.

Mothers' breastfeeding knowledge has been found significantly associated with EBF. Mothers who knew the importance of exclusive breastfeeding were 1.46 times more likely to exclusively breastfed their infants than those who did not know the importance of EBF. This has a similarity with a study finding from Mecha district, North West Ethiopia(18). This indicates improved knowledge of mothers about the benefits of breastfeeding helps for the health of themselves and their infants.

The finding of this study indicates that the odds of practicing EBF among women who attended by a health care provider in a health facility during childbirth were 1.5 times more likely to exclusively breastfeed their infants than those who were delivered in the home. This study finding is consistent with study findings in Northern Ghana (19) and India (5). An explanation for the observed association in this study could be that mothers who gave birth with the help of health care providers in health facilities might get the opportunity to be counseled by the delivery attendant on the benefits of early initiation and maintenance of exclusive breastfeeding up to six months.

Women who have information about exclusive breastfeeding were 2.34 times more likely to exclusively breastfed than those who have no information. This finding is in line with a study conducted in East Ethiopia (20).

In this study, mothers' attendance of ANC service during their pregnancy was significantly associated with exclusive breastfeeding for infants less than six months old. Those mothers who received ANC service were 2.31 times more likely to exclusively breastfed their infants compared to those who did not receive ANC service. This result is consistent with the study finding in Mecha district, North West Ethiopia (18). This might be due to the counseling of mothers on the importance of breastfeeding in the health facilities during the service delivery.

\section{Strength of the study}

The study used a mix of quantitative and qualitative methods that adds value to make it a stronger study design.

\section{Limitation of the study}

Breastfeeding mothers may interrupt exclusive breastfeeding at age of fewer than six months after the interview. As a result, this study may not include the recommended length of exclusive breastfeeding (six months) for all exclusive breastfeeding mothers.

\section{Conclusions}

The prevalence of exclusive breastfeeding among breastfeeding mothers with infants aged less than six months in the study area was $70.8 \%$. Factors associated with EBF were the age of mothers, antenatal 
care service utilization, place of birth, mother's information about exclusive breastfeeding, and knowledge of mothers about the importance of exclusive breastfeeding contributed to exclusive breastfeeding of infants less than six months old. Therefore, health care providers should raise awareness and encourage pregnant women to attend health facilities for ANC and delivery, and encourage breastfeeding counseling during visits. The District Health Office should develop strategies to improve awareness about exclusive breastfeeding by integrating with concerned bodies to reduce non-optimal breastfeeding practices.

\section{Abbreviations}

ANC: Antenatal Care; AOR: Adjusted Odd Ratio; Cl: Confidence Interval; COR: Crude Odd Ratio; EBF: Exclusive Breastfeeding; FGD: Focus Group Discussion; KI: Key Informant; PI; Principal Investigator; PNC: Postnatal Care; WHO: World Health Organization;

\section{Declarations}

\section{Ethics approval and consent to participate}

Ethical clearance was obtained from the Institutional Ethical Review Board of Rift Valley University, Ambo Campus School of Public Health, and submitted to Nono District Health Office. An official letter of permission was written to the respective kebeles by the district health office. Informed oral consent was obtained from study participants after explaining the objective of the study, the benefit, and the risks of participating in this study.

\section{Consent for publication}

The Ethics committee approved that the finding of the study could publish since identifying images or clinical details of participants that compromise anonymity was not applicable.

\section{Availability of data and materials}

All data supporting our findings are already described and included in the manuscript.

\section{Competing interests}

The authors declared that they have no competing interests.

\section{Funding}

The authors declared that there was no funding source. 


\section{Authors' contributions}

GF: participated in topic selection, design of the study, performed the data collection, and performed the statistical analysis. TS: participated in the design of the study, statistical analysis, contributed to the finalization of the manuscript, and served as the lead author of the manuscript. TG: participated in the design and statistical analysis. All authors read and approved the final manuscript.

\section{Acknowledgments}

Authors are very grateful to the supervisors, data collectors, respondents, and all other individuals for their contributions.

\section{Authors' information}

${ }^{1}$ West Shewa Zonal Health Department, Ambo, Ethiopia; gerbafufa24@gmail.com

${ }^{2}$ Ethiopian Public Health Institute, Addis Ababa, Ethiopia; abdiikoo50@gmail.com

${ }^{3}$ Public Health Department, Ambo University, Ambo, Ethiopia; teka_girma@yahoo.com

\section{References}

1. Abdulmalek LJ. Factors affecting exclusive breastfeeding practices in Benghazi, Libya. Breast. 2018;4:2.

2. Joshi PC, Angdembe MR, Das SK, Ahmed S, Faruque ASG, Ahmed T. Prevalence of exclusive breastfeeding and associated factors among mothers in rural Bangladesh: a cross-sectional study. International breastfeeding journal. 2014;9(1):1-8.

3. Mohamed AA, Mohamud SA, Mohamud FY, Ali KA, Abdulle FA, Hussein AA. Prevalence and Associated Factors of Exclusive Breastfeeding Practices Among Mothers of Infants Less Than Six Months in Galkayo, Somalia: A Community Based Cross-Sectional Study. Sci J Public Health. 2018;6(5):133-9.

4. Azeze GA, Gelaw KA, Gebeyehu NA, Gesese MM, Mokonnon TM. Exclusive breastfeeding practice and associated factors among mothers in Boditi Town, Wolaita Zone, Southern Ethiopia, 2018: a community-based cross-sectional study. International Journal of pediatrics. 2019;2019.

5. Ogbo FA, Dhami MV, Awosemo AO, Olusanya BO, Olusanya J, Osuagwu UL, et al. Regional prevalence and determinants of exclusive breastfeeding in India. International breastfeeding journal. 2019;14(1):1-12.

6. Mamo K, Dengia T, Abubeker A, Girmaye E. Assessment of Exclusive Breastfeeding Practice and Associated Factors among Mothers in West Shoa Zone, Oromia, Ethiopia. Obstetrics and gynecology 
international. 2020;2020.

7. Mundagowa PT, Chadambuka EM, Chimberengwa PT, Mukora-Mutseyekwa F. Determinants of exclusive breastfeeding among mothers of infants aged 6 to 12 months in Gwanda District, Zimbabwe. International breastfeeding journal. 2019;14(1):1-8.

8. Dr. Arun Gupta, Dr. JP Dadhich, Patti Rundall, Bidla N. Interpreting the World Health Assembly Targets on Exclusive Breastfeeding by 2025.

9. Woldeamanuel BT. Trends and factors associated to early initiation of breastfeeding, exclusive breastfeeding and duration of breastfeeding in Ethiopia: evidence from the Ethiopia demographic and health survey 2016. International breastfeeding journal. 2020;15(1):1-13.

10. Wanjohi M, Griffiths P, Wekesah F, Muriuki P, Muhia N, Musoke RN, et al. Sociocultural factors influencing breastfeeding practices in two slums in Nairobi, Kenya. International breastfeeding journal. 2016;12(1):1-8.

11. Abera M, Abdulahi M, Wakayo T. Fathers' involvement in breastfeeding practices and associated factors among households having children less than six months in Southern Ethiopia: a crosssectional study. Pediatr Ther. 2017;7(1):1000306.

12. office Ndh. Nono district health office: Annual report, 2019: Silkamba, West Shewa Zone, Ethiopia. Nono district health office, 2019.

13. Setegn T, Belachew T, Gerbaba M, Deribe K, Deribew A, Biadgilign S. Factors associated with exclusive breastfeeding practices among mothers in Goba district, southeast Ethiopia: a crosssectional study. International breastfeeding journal. 2012;7(1):1-8.

14. Bayissa ZB, Gelaw BK, Geletaw A, Abdella A, Alemayehu A, Yosef A, et al. Knowledge and practice of mothers towards exclusive breastfeeding and its associated factors in Ambo Woreda West Shoa Zone Oromia Region, Ethiopia. International Journal of Research and Development in Pharmacy \& Life Sciences. 2015;4(3):1590-7.

15. Liben ML, Gemechu YB, Adugnew M, Asrade A, Adamie B, Gebremedin E, et al. Factors associated with exclusive breastfeeding practices among mothers in dubti town, Afar regional state, northeast Ethiopia: a community based cross-sectional study. International breastfeeding journal. 2016;11(1):1-6.

16. Hunegnaw MT, Gezie LD, Teferra AS. Exclusive breastfeeding and associated factors among mothers in Gozamin district, northwest Ethiopia: a community-based cross-sectional study. International Breastfeeding Journal. 2017 2017/07/10;12(1):30.

17. Bomfim LTM, Novaes TF, Bonanato K, Navarro RS, Tedesco TK, Imparato JCP, et al. Factors related to the practice of exclusive breastfeeding in different cities of the States Minas Gerais and Bahia, Brazil. Pesquisa Brasileira em Odontopediatria e Clínica Integrada. 2017;17(1):1-10.

18. Mazengia AL, Demissie H. Knowledge, and Practice of Employed Mothers towards Exclusive Breastfeeding and Its Associated Factors in Mecha district, Northwest Ethiopia. Journal of Nutrition and Metabolism. 2020;2020. 
19. Iddrisu S. Exclusive breastfeeding and family influences in rural Ghana: a qualitative study. Malmö högskola/Hälsa och samhälle; 2013.

20. Egata G, Berhane Y, Worku A. Predictors of non-exclusive breastfeeding at 6 months among rural mothers in east Ethiopia: a community-based analytical cross-sectional study. International breastfeeding journal. 2013;8(1):1-8.

\section{Tables}

Table 1

\begin{tabular}{llll}
\hline Characteristics & Category & Number & Percent \\
\hline Age of mother (years) & $15-19$ & 16 & 2.8 \\
\cline { 2 - 4 } & $20-24$ & 114 & 20.2 \\
\cline { 2 - 4 } & $25-29$ & 204 & 36.1 \\
\cline { 2 - 4 } & $30-34$ & 151 & 26.7 \\
\cline { 2 - 4 } & $\geq 35$ & 80 & 14.2 \\
\hline \multirow{2}{*}{ Religion of mother } & Orthodox & 330 & 58.4 \\
\cline { 2 - 4 } & Muslim & 147 & 26.0 \\
\cline { 2 - 4 } & Protestant & 87 & 15.4 \\
\cline { 2 - 4 } & Others* & 1 & 0.2 \\
\cline { 2 - 4 } & Total & 565 & 100.0 \\
\hline Ethnicity of mother & Oromo & 463 & 81.9 \\
\cline { 2 - 4 } & Amhara & 91 & 16.1 \\
\cline { 2 - 4 } & Others** & 11 & 1.9 \\
\hline Educational status mother & Can't read \& write & 342 & 60.5 \\
\cline { 2 - 4 } & Primary(1-8) & 178 & 31.5 \\
\cline { 2 - 4 } & Secondary \& above & 45 & 8.0 \\
\hline Occupation of mother & Housewife & 493 & 87.3 \\
\cline { 2 - 4 } & Government employed & 19 & 3.4 \\
\cline { 2 - 4 } & Private organization & 1 & 0.2 \\
\cline { 2 - 4 } & Merchant & 29 & 5.1 \\
\cline { 2 - 4 } & Daily laborer & 23 & 4.1 \\
\cline { 2 - 4 } & Single & 547 & 0.7 \\
\cline { 2 - 4 } & Married & 146.8 \\
\cline { 2 - 4 } & Others*** & 2.5 \\
\hline Marital status & & & 4 \\
& &
\end{tabular}

Key: *Waqeffata, **Gurage, Tigire and Kambata, ***Widowed, Divorced and Separated

Table 2 


\begin{tabular}{|c|c|c|c|}
\hline Characteristics & Category & Number & Percent \\
\hline \multirow[t]{2}{*}{ Sex of infant } & Male & 262 & 46.4 \\
\hline & Female & 303 & 53.6 \\
\hline \multirow[t]{4}{*}{ Age of infant (months) } & $<1$ & 85 & 15.0 \\
\hline & $1-2$ & 113 & 20.0 \\
\hline & $3-4$ & 255 & 45.1 \\
\hline & $5-6$ & 112 & 19.8 \\
\hline \multirow[t]{4}{*}{ Birth order of infant } & 1 & 87 & 15.4 \\
\hline & 2 & 118 & 20.9 \\
\hline & 3 & 138 & 24.4 \\
\hline & $\geq 4$ & 222 & 39.3 \\
\hline \multirow[t]{3}{*}{ Birth interval (years) } & $1-2$ & 218 & 38.6 \\
\hline & $3-4$ & 335 & 59.3 \\
\hline & $\geq 5$ & 12 & 2.1 \\
\hline \multirow[t]{2}{*}{ Antenatal care services } & Yes & 518 & 91.7 \\
\hline & No & 47 & 8.3 \\
\hline \multirow{2}{*}{$\begin{array}{l}\text { Counseled about breastfeeding during Antenatal } \\
\text { Care (ANC) }\end{array}$} & Yes & 518 & 91.7 \\
\hline & No & 47 & 8.3 \\
\hline \multirow[t]{2}{*}{ Place of birth } & Health facility & 313 & 55.4 \\
\hline & Home & 252 & 44.6 \\
\hline \multirow[t]{2}{*}{ Mode of delivery } & Vaginal & 528 & 93.5 \\
\hline & $\begin{array}{l}\text { Cesarean } \\
\text { section }\end{array}$ & 37 & 6.5 \\
\hline \multirow[t]{2}{*}{ Postnatal care } & Yes & 305 & 54.0 \\
\hline & No & 260 & 46.0 \\
\hline \multirow{2}{*}{$\begin{array}{l}\text { Counseled about breastfeeding during Postnatal } \\
\text { Care (PNC) }\end{array}$} & Yes & 200 & 35.4 \\
\hline & No & 365 & 64.6 \\
\hline
\end{tabular}

Table 3 


\begin{tabular}{|c|c|c|c|}
\hline Characteristics & Category & Number & Percent \\
\hline \multirow[t]{2}{*}{ Colostrum feeding } & Yes & 507 & 89.7 \\
\hline & No & 58 & 10.3 \\
\hline \multirow[t]{2}{*}{$\begin{array}{l}\text { Time interval within breastfeeding started after } \\
\text { birth }\end{array}$} & $\begin{array}{l}\text { Immediately within } \\
1 \text { hour }\end{array}$ & 400 & 70.8 \\
\hline & 1 hour up to 1 day & 165 & 29.2 \\
\hline \multirow[t]{4}{*}{$\begin{array}{l}\text { Reason of delaying breastfeeding more than one } \\
\text { hour }\end{array}$} & $\begin{array}{l}\text { Caesarean } \\
\text { delivery }\end{array}$ & 35 & 21 \\
\hline & Infant illness & 17 & 10 \\
\hline & Maternal illness & 29 & 18 \\
\hline & $\begin{array}{l}\text { Delayed milk } \\
\text { secretion }\end{array}$ & 84 & 51 \\
\hline \multirow[t]{3}{*}{$\begin{array}{l}\text { Type of additional food given to infant before } \\
\text { the breast start to flow in the first 3days }\end{array}$} & $\begin{array}{l}\text { Nothing other than } \\
\text { breast milk }\end{array}$ & 543 & 96 \\
\hline & Butter & 7 & 1.3 \\
\hline & Caw milk & 15 & 2.7 \\
\hline \multirow{2}{*}{$\begin{array}{l}\text { Additional food given to infant in the previous } 24 \\
\text { hours }\end{array}$} & Yes & 165 & 29.2 \\
\hline & No & 400 & 70.8 \\
\hline \multirow[t]{4}{*}{ The reason of giving additional food to infant } & $\begin{array}{l}\text { Decreased milk } \\
\text { secretion }\end{array}$ & 22 & 13.3 \\
\hline & $\begin{array}{l}\text { Breast milk only } \\
\text { not sufficient }\end{array}$ & 113 & 68.5 \\
\hline & Infant is thirsty & 13 & 7.9 \\
\hline & Workload & 17 & 10.3 \\
\hline \multirow[t]{5}{*}{ Who advised you on feeding of your infant } & Husband/spouse & 128 & 22.7 \\
\hline & My mother & 70 & 12.4 \\
\hline & Mother in law & 5 & 0.9 \\
\hline & Health worker & 60 & 10.6 \\
\hline & My own decision & 302 & 53.5 \\
\hline \multirow[t]{3}{*}{ Role of husband in exclusive breast feeding } & He gives advice & 328 & 58.1 \\
\hline & $\begin{array}{l}\text { Give economic } \\
\text { Support }\end{array}$ & 154 & 27.3 \\
\hline & Has no role & 83 & 14.7 \\
\hline
\end{tabular}

Table 4 


\begin{tabular}{|c|c|c|c|c|c|c|}
\hline \multirow[t]{2}{*}{ Characteristics } & \multirow[t]{2}{*}{ Category } & \multicolumn{2}{|c|}{$\begin{array}{c}\text { EBF } \\
\text { practice }\end{array}$} & \multirow{2}{*}{$\begin{array}{c}\text { COR } \\
(95 \% \mathrm{CI})\end{array}$} & \multirow{2}{*}{$\begin{array}{l}\text { AOR }(95 \% \\
\text { CI) }\end{array}$} & \multirow{2}{*}{$\begin{array}{l}\text { P- } \\
\text { Value }\end{array}$} \\
\hline & & Yes & No & & & \\
\hline \multirow[t]{5}{*}{ Age of mothers } & $15-19$ & 7 & 9 & $\begin{array}{l}3.49 \\
(1.19, \\
5.48)^{*}\end{array}$ & $\begin{array}{l}1.53 \\
(0.22 \\
2.41)\end{array}$ & 0.08 \\
\hline & $20-24$ & 31 & 49 & $\begin{array}{l}2.04 \\
(1.09, \\
3.80)^{*}\end{array}$ & $\begin{array}{l}2.67 \\
(1.79 \\
4.60)^{*}\end{array}$ & 0.04 \\
\hline & $25-29$ & 50 & 93 & $\begin{array}{l}1.67 \\
(0.97 \\
2.88) \\
\end{array}$ & $\begin{array}{l}1.23 \\
(0.72, \\
2.50)\end{array}$ & 0.72 \\
\hline & $30-34$ & 56 & 140 & $\begin{array}{l}1.28 \\
(0.70 \\
2.24) \\
\end{array}$ & $\begin{array}{l}1.13 \\
(0.56 \\
2.77)\end{array}$ & 0.21 \\
\hline & $\geq 35$ & 28 & 102 & 1 & 1 & 1 \\
\hline \multirow[t]{2}{*}{ Antenatal care service } & Yes & 140 & 378 & $\begin{array}{l}3.07 \\
(1.68, \\
5.62)^{*} \\
\end{array}$ & $\begin{array}{l}2.31 \\
(1.31 \\
4.71)^{*}\end{array}$ & 0.00 \\
\hline & No & 25 & 22 & 1 & 1 & 1 \\
\hline \multirow[t]{2}{*}{ Place of birth } & $\begin{array}{l}\text { Health } \\
\text { facility }\end{array}$ & 233 & 80 & $\begin{array}{l}1.48 \\
(1.03 \\
2.13)^{*}\end{array}$ & $\begin{array}{l}1.34 \\
(1.21 \\
2.11)^{*}\end{array}$ & 0.03 \\
\hline & Home & 167 & 85 & 1 & 1 & 1 \\
\hline \multirow[t]{2}{*}{$\begin{array}{l}\text { Mothers have information about } \\
\text { EBF }\end{array}$} & Yes & 221 & 117 & $\begin{array}{l}1.97 \\
(1.34 \\
2.91)^{*} \\
\end{array}$ & $\begin{array}{l}2.34 \\
(1.13 \\
4.76)^{*} \\
\end{array}$ & 0.00 \\
\hline & No & 179 & 48 & 1 & 1 & 1 \\
\hline \multirow[t]{2}{*}{$\begin{array}{l}\text { Mothers know importance of } \\
\text { EBF for maternal health }\end{array}$} & Yes & 339 & 156 & $\begin{array}{l}3.12 \\
(1.51 \\
6.44)^{*} \\
\end{array}$ & $\begin{array}{l}1.46 \\
(1.12, \\
3.73)^{*} \\
\end{array}$ & 0.04 \\
\hline & No & 61 & 9 & 1 & 1 & 1 \\
\hline
\end{tabular}

Key: *=Significant association $(\mathrm{P}<0.05$ at $95 \% \mathrm{CI})$ 